\title{
Introduction: Semantics and Philosophy
}

\author{
Maria Aloni $^{1} \cdot$ Franz Berto $^{1} \cdot$ Luca Incurvati $^{1} \cdot$ Floris Roelofsen $^{1}$
}

Published online: 17 August 2017

(c) Springer Science+Business Media B.V. 2017

Many crucial insights into the use of language in communication and reasoning have emerged from work at the interface of formal semantics and philosophy. This special issue contains a small selection of papers presented at the 20th edition of the Amsterdam Colloquium, organized by the Institute for Logic, Language, and Computation at the University of Amsterdam. Since the 1980s, this bi-annual event has been one of the primary venues for work addressing foundational issues in the theory of meaning as well as indepth analyses of specific linguistic phenomena. The special issue features contributions by some of the most renowned semanticists and philosophers. It highlights some of the main recent advances, raises new issues, and will hopefully spark new interactions between the two disciplines.

The articles contained in the special issue centre on three topics: conditionals (Williamson, Priest, and Willer), quantifiers (Romero and Renans), and negation (Zeijlstra).

Timothy Williamson's contribution is concerned with "Counterpossibles", subjunctive or counterfactual conditionals whose antecedent is true in no possible world. Williamson defends a view referred to as vacuism: all counterpossibles are vacuously or trivially true, independently of the se-mantic contribution of their consequent. Common sense seems to deliver the opposite verdict: some counterpossibles intuitively appear to be false ('If Mary had managed to square the circle, kangaroos would have rejoiced in Australia'), others true but not trivially so ('If Mary had managed to square the circle, mathematicians from all over the world would have been amazed'). Williamson sets out

Floris Roelofsen

f.roelofsen@uva.nl

1 ILLC, University of Amsterdam, Amsterdam, The Netherlands to explain away non-vacuist intuitions. According to him, when evaluating a conditional of the form 'If it had been the case that $A$, then it would have been the case that $B$ ' we adopt a certain heuristic, which works in most everyday life cases, but can lead us astray in peculiar circumstances-in particular, when $A$ expresses an absolute impossibility. Williamson draws a comparison with vacuous universal quantification: when $G$ and $H$ are contraries, we tend to infer the falsity of 'Every $F$ is $G$ ' from the truth of 'Every $F$ is $H$ '. However, both can be true if there are no $F$ s. Similarly, accepting 'If it had been the case that $A$, then it would have been the case that $B$ ' leads us to reject 'If it had been the case that $A$, then it would have been the case that $B$ '. But this heuristic fails when there is no way for $A$ to be true. Williamson argues that we are-or can become-aware of the fallibility of such heuristics, as shown in proofs by reductio ad absurdum expressed using counterfactuals, and adds that non-vacuists have problems in accounting for (such formulations of) reductio proofs.

Graham Priest, in his article "Some new thoughts on conditionals", attempts to bridge the gap between ceteris paribus indicative and subjunctive or counterfactual conditionals. He proposes a unified account of indicatives and subjunctives in terms of information transfer between worlds. We evaluate a ceteris paribus conditional with antecedent $\mathrm{A}$ and consequent $\mathrm{B}$ by considering a selection of situations where $\mathrm{A}$ is true, and seeing if $\mathrm{B}$ is true there. The selection is governed by the (heavily context-dependent) importation of information we have in the situation we find ourselves in. The Priestian framework entails a rejection of the view that ceteris paribus indicatives are, in general, not truth-apt. It accounts for the logical similarity between indicatives and subjunctives (in particular, their failing Contraposition, Antecedent Strengthening, and Transitivity), while their semantic differences are explained by claiming that 
the mood of the two kinds of conditional leads us to import information in different ways, also when the respective antecedents and consequents coincide. The view also accounts for the difference between past and present subjunctives by claiming that the former determine a temporal backshift of the point of evaluation, absent in the latter, which changes the imported information. Priest provides a sketch of how his view may solve a number of open problems in the semantics of conditionals, and answers some objections.

Malte Willer, in his article "Simplifying with free choice", seeks a unified explanation of (i) the fact that counterfactual conditionals license simplification of disjunctive antecedents ('If A or B had come, the party would have been fun' implies that 'If A had come, the party would have been fun'), and (ii) the fact that disjunctions scoping under possibility modals give rise to so-called free choice effects ('John might be in London or in Paris' implies that 'John might be in London'). He shows that the data are well explained by a dynamic semantic analysis of conditionals and modals that uses ideas from the inquisitive semantics tradition in its treatment of disjunction, and he explains in particular why disjunctions in counterfactual antecedents and possibility statements revert to their classical behaviour when embedded under negation.

Maribel Romero, in her article "The conservativity of many: split scope and most" discusses reverse proportional readings of many (and few) which have been argued to challenge the universal that determiners in natural language are always interpreted as conservative functions. In recent proposals Romero defended an analysis of many which preserves conservativity and derives re-verse proportional readings by decomposing the determiner into two independent parts, a determiner stem many and a focusing operator POS, the latter familiar from degree analyses of positive forms of adjectives. In this analysis, reverse proportional readings follow on a proportional interpretation of many by letting POS associate with the focal alternatives generated within the host NP (as in 'Many Scandinavian ${ }_{F}$ have won the Nobel Prize in literature'). Romero's present article critically evaluates two predictions of this proposal: (i) the prediction that a third operator, e.g., an attitude verb, may intervene between many and pos generating new 'split scope' readings; and (ii) the prediction that reverse proportional readings of most are expected to arise in languages where the superlative degree operator -est shows the same versatility of POS in English (namely allowing association internal and external to the host NP). Both predictions are shown to be borne out.

Agata Renans, in her article "Two types of choice-functional indefinites: evidence from $\mathrm{Ga}$ ", discusses the interpretation of two indefinite determiners in $\mathrm{Ga}$, a language spoken in Ghana, and proposes an account that requires two kinds of choice-functional variables. Choice-functions have been employed in the semantic literature to account for the exceptional scope of indefinite noun phrases which, in contrast to canonical quantifiers, can escape so-called syntactic islands. Choice-function analyses of indefinites disagree on whether choice-functional variables are existentially bound or remain free. Renans argues that Ga indefinites present evidence that both options are realised in natural language: focusing on scopal interactions with negation and universal noun phrases she concludes that kome indefinites are to be analyzed as free skolemized choice-functions (whose pronominal parameter can be bound either by the context or by a wider scope quantificational NP) while $k o$ indefinites are to be analysed as existentially bound skolemized choicefunctions (whose pronominal parameter has to be bound by a quantificational NP, if available).

Finally, Hedde Zeijlstra, in his article "Does neg-raising involve neg-raising?", discusses the phenomenon that certain negated predicates allow for an interpretation under which the negation seems to take scope below the predicate itself (for instance, 'Susan doesn't think that she will pass the exam' has a salient reading under which Susan thinks that she won't pass the exam). Zeijlstra defends the pragmasemantic approach to this phenomenon against recently voiced criticisms. He provides a number of novel arguments in favour of the approach and against its syntactic competitor.

We are very grateful to the authors for their exciting contributions, to the reviewers for their constructive feedback, and to Topoi Editor-in-Chief Fabio Paglieri for his editorial guidance. We hope that the various perspectives represented in the special issue will be inspiring to semanticists, philosophers, and everyone in between. 